\title{
Pricing Strategies of Dual-Recycling Channels considering Refurbishing and Remanufacturing of WEEE
}

\author{
Manyi Tan $\mathbb{D}^{\mathbb{D}}$, Bin Wang $\mathbb{D}$, Kaiwen Zheng, and Hong Cheng $\mathbb{D}$ \\ College of Management Science, Chengdu University of Technology, Chengdu, China \\ Correspondence should be addressed to Hong Cheng; anne.cheng@163.com
}

Received 26 October 2021; Accepted 30 December 2021; Published 22 January 2022

Academic Editor: Nikunja Mohan Modak

Copyright (C) 2022 Manyi Tan et al. This is an open access article distributed under the Creative Commons Attribution License, which permits unrestricted use, distribution, and reproduction in any medium, provided the original work is properly cited.

\begin{abstract}
This article studies pricing strategies of the dual-channel recycling supply chain where the manufacturer and the recycler compete on price in recycling waste electrical and electronic equipment (WEEE) and cooperate in disposing of them. This article is based on whether the recycler can refurbish and distinguish two different treatment methods of WEEE: refurbishment by the recycler and remanufacturing by the manufacturer. Two dual-channel recycling structures are proposed: (1) the recycler cannot refurbish when the manufacturer remanufactures; (2) the recycler can refurbish when the manufacturer remanufactures. By solving two Stackelberg game models, we derive pricing strategies. The impacts of recycled products' quality and base profit for remanufacturing and refurbishing on pricing strategies are discussed. We find that the recycler prefers refurbishing when its base profit for refurbishment is greater than the manufacturer's base profit for remanufacturing, rather than the transfer price. Interestingly, the recycler's refurbishment does not reduce the manufacturer's profits but creates a win-win situation through their cooperation. Furthermore, the better quality of recycled products and the higher base profit for refurbishing and remanufacturing can bring more profit to the recycler and the manufacturer, increase the recycling prices, improve the efficiency of resource utilization, and reduce environmental pollution.
\end{abstract}

\section{Introduction}

The progress of science and technology has greatly shortened the life cycle of electrical and electronic products, and the speed of product replacement is getting faster and faster, putting tremendous pressure on the environment; therefore, a large number of electronic waste products need to be processed $[1,2]$.

Reasonable and effective recycling and disposal of WEEE has become a universal concern worldwide [3]. Since waste electrical and electronic equipment (WEEE) contains many harmful chemical substances, it will not only affect human health but also threaten the natural environment [4]. Recycling WEEE also has economic value. Due to the particularity of WEEE, many parts contained in used products can be recycled and reused [5]. Recycling and reusing used products can help solve the shortage of raw materials [6]. For example, Xerox dismantles recycled copiers and reused them. The new copiers produced from reused parts save approximately $40 \%-65 \%$ of the cost compared with before [7]. For enterprises, compared with the production of new products, reproducing and remanufacturing can save approximately $50 \%$ of the cost and can save approximately $60 \%$ of energy and $70 \%$ of materials [8]. Therefore, recycling WEEE is beneficial from the perspective of environmental protection and company interests [3].

When WEEE is recycled, it will undergo a series of activities, such as refurbishing, re-manufacturing, and dismantling $[9,10]$. From the view of public, cost can be saved and profit can be improved if this series of activities is taken according to the quality of WEEE. By disposing of different types and qualities of waste electronic products in different ways, the recycling efficiency of waste electronic products can be improved.

According to a survey conducted in 2014 by Liquidity Services, a global solution provider for the reverse supply chain, among the 1407 respondents, 94\% had purchased refurbished products in the past three years, $81 \%$ suggested 
buying refurbished products from others, and more consumers will accept refurbished products in the future (https://www.businesswire.com/). The huge market demand has attracted many recyclers to carry out refurbishment work. Take China's internet recycler Aihuishou (https:// www.aihuishou.com/) as an example. When it collects WEEE from consumers, unlike previous recyclers, it will classify waste products according to the quality level. The higher-quality parts will be refurbished and sold, and the parts that cannot be refurbished will be transferred to the disposal company for resource treatment or the manufacturer for remanufacturing. Therefore, the recycler makes profits from recycling and refurbishing. Aihuishou reached a cooperation agreement with Huawei in 2017, and Huawei allowed Aihuishou to recycle and refurbish products [11]. Huawei dismantles and remanufacturers used products at the same time.

As the recycler refurbishes WEEE and considering the refurbishment and remanufacturing classification of WEEE, compared with recyclers who cannot refurbish and only consider WEEE for remanufacturing, how will the income of recyclers and manufacturers change?

This article considers dual-channel recycling composed of a manufacturer and a recycler. The manufacturer and the recycler compete on price in the recycling market. After recycling, the manufacturer dismantles used products environmentally, remanufactures, and sells them to customers. If the recycler cannot refurbish used products, the recycler will only cooperate with the manufacturer in recycling, and the recycler will transfer all the used products to the manufacturer to make a profit. When the recycler can refurbish, the recycler makes a profit from refurbishing the part of the waste product with better quality and transfers the other portion to the manufacturer for profit. Therefore, the recycler and the manufacturer compete in recycling and cooperate in the remanufacturing process.

Compared with previous studies, $[5,12,13]$ have considered the reuse of waste products by different supply chain entities. They refer to refurbishment and remanufacturing collectively as remanufacturing without making a strict distinction between the two. In real life, there is a clear difference between refurbishment and remanufacturing. Refurbishment is mainly for the whole machine and does not replace the original main structure. This machine still exists with its original functions, and remanufacturing involves more parts entering the remanufacturing process [14]. Therefore, this article distinguishes between refurbishment and remanufacturing in the treatment of waste electronic products. In addition, [8, 15-17] consider that the manufacturer and the retailer have refurbishment capabilities. Different from their studies, this article considers the recycler's refurbishment. In this article, the following issues are studied:

(1) What are the conditions under which the recycler is willing to refurbish? What are the conditions under which the manufacturer wants to cooperate with the recycler with refurbishment ability?

(2) Regardless of whether the recycler has the ability to refurbish, how can the manufacturer and the recycler maximize their profits? How will the quality level of products recycled and the base profit affect their pricing decisions?

To study the above problems, we use the Stackelberg game to solve the model, and we discover an interesting conclusion, which is different from what we used to think. The recycler is willing to refurbish and the manufacturer is willing to cooperate with the recycler with refurbishment capability, if and only if the recycler's base profit for refurbishment is greater than the manufacturer's base profit of remanufacturing, instead of the transfer payment. In addition, we get some contributions. First, we have enriched the research on cooperation and competition in dualchannel recycling. Then, we discovered the boundary conditions of recyclers willing to carry out refurbishment activities. At the same time, we found that the refurbishment of recyclers would benefit manufacturers, the supply chain, and environmental protection when the recycler's basic profit for refurbishing is greater than the manufacturer's basic profit for remanufacturing. Finally, by analyzing the quality level of WEEE, the base profit for remanufacturing, or refurbishing, some management insights are provided.

The rest of this paper is organized as follows. In the next section, the relevant literature review is given. Section 3 describes the model settings and solves them. In Section 4, the equilibrium solutions were analyzed and compared. In Section 5, a numerical analysis is carried out to verify and extend the propositions. Finally, conclusions and future research directions are given in Section 6. All proofs in the article are given in the Appendix.

\section{Literature Review}

This study discusses the conditions for refurbishment and coopetition strategies of manufacturers and third-party recyclers in a dual-channel recycling supply chain by constructing and comparing two Stackelberg game models. The literature related to this study mainly focuses on competition and cooperation between recycling channels and the disposal of WEEE.

2.1. Channel Competition. Most literature on reverse supply chains has focused on competition between channels. Reference [5] proposed three recycling modes of manufacturers, retailers, and third parties and discussed the selection of recycling channels by developing game theory models. A large number of scholars expanded their study to issues related to competition. Reference [18] considered total social welfare as a parameter; two dual-channel recycling models were constructed. Manufacturers competed with retailers and third parties, respectively, compared with a singlechannel recycling model. It is found that the efficiency of dual-channel recycling is always better than the singlechannel one, and it is recommended to introduce competition in recycling activities in their study.

Researchers are looking for factors affecting recycling efficiency. Reference [19] established two closed-loop supply chain competition models under uncertain environments 
and analyzed how the price competition coefficient affects the change in the amount of waste recycling. Reference [20] through a supply chain composed of two competing recyclers; using the Stackelberg game to analyze the recycling situation under uncertain market demand, it is found that the competition coefficient of the third-party recycler will affect the recycling volume. Reference [21] constructed a quality-based dual-channel recycling competition model for the WEEE market, and the impact of government subsidies on recycling effects under different competitive environments was discussed.

In addition to the impact on recycling efficiency, competition also has an impact on the recycling decision. Reference [22] compared single-channel and dual-channel competition and found that the intensity of channel competition affects the wholesale and sale prices of new products. Reference [23] analyzed the influence of the competition between the manufacturer and the remanufacturer on the production and pricing in the sale market and the recycling market and obtained the optimal strategy of both parties by establishing the Nash equilibrium. Reference [24] analyzed the CLSC model in which the retailer competed with a third-party recycler for recycling. By comparing it with the optimal decision of dual-channel and single-channel recycling, it is found that the optimal decision of recycling depends on the competition intensity of the dual-recycling channel. Reference [25] constructed three two-channel recycling game models, and the Stackelberg game was used to find that regardless of how the intensity of competition between recycling channels changes, the OEM and retailer dual collecting model is the best option for the OEM.

The above literature studied the competition between traditional recycling channels. However, with the development of information technology, the operation of recycling on the internet has emerged. With low recycling and transportation costs, internet recycling has become a new and effective recycling channel. Reference [26] used the Stackelberg game to study the dual recycling channel model consisting of traditional recycling and online recycling, and they found that traditional and online recycling channels competed on recycling price. Reference [27] found that competition between recycling channels forcibly increases recycling prices and ultimately improves recycling efficiency. Reference [28] also used optimization analysis and a Stackelberg game to analyze the impact of competition between offline and online recycling channels on recycling prices.

These documents have performed much research on the recycling efficiency and decision influencing factors in the case of channel competition. However, there is not only competition but also cooperation between channels, which is ignored by these studies.

2.2. Channel Cooperation. In addition to the study on competition in the recycling channel, cooperation in the recycling channel attracts much attention. To improve recycling efficiency, it has become normal for manufacturers to commission recycling to other recycling companies. In [29], as mentioned earlier, to improve recycling efficiency and achieve a green supply chain, a large number of companies cooperate with third-party recyclers in reverse logistics activities. Reference [30] also stated that in a complex business environment, the company would work with third parties to conduct recycling and remanufacturing activities, and the scholars combed through the literature and found that the selection of third-party partners must be considered from multiple perspectives.

How should manufacturers cooperate with other recyclers in the recycling process? Reference [31] constructed a dual closed-loop supply chain model and studied how manufacturers, retailers, and third-party recyclers cooperate in recycling using a Stackelberg game. Manufacturers should reasonably coordinate the recycling efforts of retailers and recyclers. Reference [32] proposed that manufacturers provided a third party with a contract fee for cooperative recycling. It was proven that this recycling form is a win-win for manufacturers and the public. Reference [33] proposed a two-stage dynamic game, consisting of a manufacturer and a third-party recycler. The manufacturer entrusts the third party to assist in recycling through contract payment. The optimal contract payment between the third party and the manufacturer was obtained by developing game theory methods. In addition to the study on how recycling channels cooperate, some studies have also analyzed factors that affect the cooperation of recycling channels. Reference [34] found that cooperation between the dual channels was affected by bargaining power and cost through quantitative analysis of the probability of cooperation between the dual channels.

Internet development enables the cooperation mode of recycling channels from offline to online. Online recycling further promotes the development of reverse recycling channels and helps solve the current problems faced by traditional recycling [35]. It is very common in the supply chain that the dual-recycling channel consists of traditional and online recycling, and some literature has focused on it. Reference [36] applied the cost-sharing mechanism to coordinate the recycling amount between the third-party recycler and the retailer. Reference [37] compared centralized and decentralized decision-making to obtain the optimal decision and maximum profit by developing the Stackelberg game.

These documents have much research on channel cooperation forms and influencing factors, but few studies consider the coexistence of competition and cooperation simultaneously. In real life, the relationship between channels is often more complicated. In addition, the situation of competition and cooperation under different disposals of WEEE is not considered.

2.3. Disposal Methods for WEEE. After WEEE is recycled, differentiated treatment is carried out according to different quality levels. Poor quality is disassembled, useful material parts are extracted for remanufacturing, and better quality is refurbished and sold [21]. Reference [14] believed that there is a fundamental difference between remanufacturing and 
refurbishment. Refurbishment is mainly for the whole machine and does not replace the original main structure. This machine still exists with its original functions. Remanufacturing involves more parts entering the remanufacturing process. For example, large companies such as Hewlett-Packard and Fuji Xerox encourage customers to participate in recycling and remanufacturing waste products. Reference [38] studied the profitability of manufacturers from remanufacturing waste products using a Stackelberg game and found that manufacturers would choose to cooperate with recyclers to make profits. On this basis, [39] studied the optimal selling price strategies of remanufactured and new products. Reference [40] considered remanufacturing by a third party and using game theory-related theories. It was found that remanufacturing by a third party is also beneficial to the original equipment manufacturer under certain conditions. Reference [27] considered the uncertainty of demand when remanufactured products are sold and studied remanufacturers' recycling strategy when they carry out mixed recycling channels.

As consumers' awareness of environmental protection has increased, consumers' acceptance of refurbished products has become higher [18]. Currently, few studies on the refurbishment of used electronic products exist. However, in real life, many electronic product manufacturers have carried out refurbishment plans for used products [41]. Reference [42] researched the refurbishment and resale of returned products and used operations research-related theories to obtain the best-selling price and the best refurbishment ratio for refurbished products. Reference [17] studied a supply chain consisting of a retailer and a manufacturer using the game theory method to analyze the manufacturer's pricing of the retailer's refurbishment authorization fees. In these discussions of research and renovation, the simultaneous existence of competition and cooperation has been neglected.

In summary, the competition and cooperation between different recycling channels are extensively studied. However, by combining the previous literature, we find that reverse supply chain relationships with both competition and cooperation are rarely considered. At the same time, we found that most studies focused on the refurbishment of manufacturers and retailers. However, they ignore the refurbishment by the recyclers. Finally, we found that most studies collectively refer to refurbishment and remanufacturing as remanufacturing, but there is a clear difference between refurbishment and remanufacturing. In this study, we differ from previous studies by considering competition and cooperation simultaneously in dual-channel recycling. We study the influence of recyclers' refurbishment capabilities on pricing strategies and distinguish between refurbishment and remanufacturing.

\section{Model}

We built a dual-channel recycling model composed of a manufacturer and a third-party recycler. The manufacturer and the recycler compete on price in the recycling market.
After recycling, the manufacturer processes recycled products into remanufactured products and sells them to consumers. When the recycled products reach the recycler, their disposal method depends on whether the recycler has the ability to refurbish and whether used products can be refurbished. In Situation 1 (Figure 1(a)), the recycler cannot refurbish, and it will transfer all the recycled products to the manufacturer to make a profit. In addition, this is their cooperation. In Situation 2 (Figure 1(b)), the recycler can refurbish. At this time, the recycler profits from refurbishing some of the recycled products with better quality. It transfers the other part to the manufacturer, as in Situation 1.

3.1. Definition of Symbols and Basic Assumptions. The symbols used in this paper are summarized in Table 1.

To better reflect the competitive relationship between the two channels, as some similar research, we set the recycle quantity of the manufacturer and the third-party recycler as a common linear function [21], as shown in the following:

$$
\begin{aligned}
Q_{m} & =\mu_{1} r_{m}-\mu_{2} r_{t}, \\
Q_{t} & =\mu_{1} r_{t}-\mu_{2} r_{m} .
\end{aligned}
$$

Here, $\mu_{1}>\mu_{2}>0$. The total recovered quantity is equal to $Q_{m}+Q_{t}$.

3.2. Model Construction and Solution. A supply chain model including the manufacturer and the recycler was constructed based on the dual-channel recycling. The manufacturer is in a strong position in the market as a leader; the recyclers act as followers. The manufacturer and the recycler are playing a Stackelberg game.

Following the Stackelberg game framework, the manufacturer, as the leader, decides the transfer fees $b$ and recycling price $r_{m}$, and the recycler, as the follower, determines the recycling price $r_{t}$ to maximize its profit. Therefore, we use reverse induction to solve the model in two situations.

Situation 1. Recyclers cannot refurbish.

Situation 1 is a special situation of Situation 2. When $\theta=1$, it means that the recycler cannot refurbish. At this time, the profit functions of the manufacturer and the recycler are

$$
\begin{aligned}
\pi_{m 1}= & \left(\Delta_{1}-r_{m 1}\right)\left(\mu_{1} r_{m 1}-\mu_{2} r_{t 1}\right) \\
& +\left(\Delta_{1}-b_{1}\right)\left(\mu_{1} r_{t 1}-\mu_{2} r_{m 1}\right), \\
\pi_{t 1}= & \left(b_{1}-r_{t 1}\right)\left(\mu_{1} r_{t 1}-\mu_{2} r_{m 1}\right) .
\end{aligned}
$$

By solving the model, the optimal solution can be calculated as follows:

$$
\begin{gathered}
r_{m 1}=\frac{\Delta_{1}}{2}, \\
b_{1}=\frac{\Delta_{1}}{2},
\end{gathered}
$$




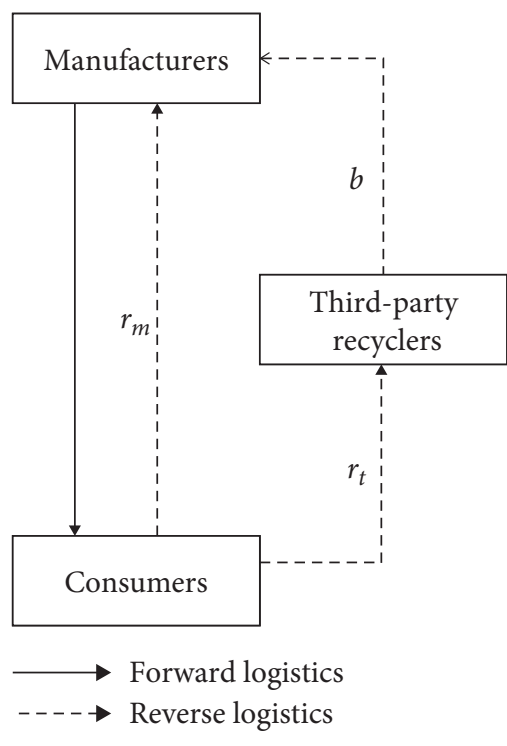

(a)

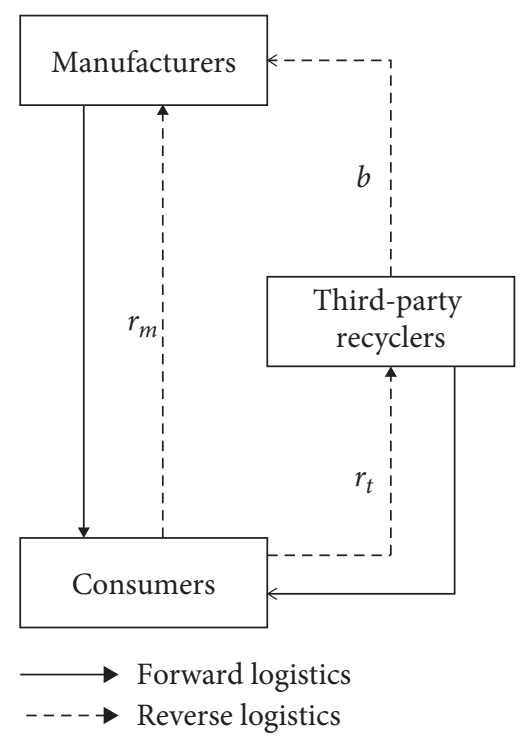

(b)

FIgURE 1: Dual-channel recycling model with coopetition. (a) Recyclers cannot refurbish. (b) Recyclers can refurbish.

TABLE 1: Definition of symbols.

\begin{tabular}{l} 
Notation \\
\hline$\pi_{i j}(i=m, t, s ; j=1,2)$ \\
$\Delta_{1}$ \\
$\Delta_{2}$ \\
$r_{t j}(j=1,2)$ \\
$r_{m j}(j=1,2)$ \\
$\left.b_{j}(j=1,2)\right)$ \\
$\theta$ \\
$Q_{i j}(i=m, t, s ; j=1,2)$ \\
$\mu_{1}$ \\
$\mu_{2}$
\end{tabular}

Substituting the recycling and transfer prices into the recycling function can obtain the number of recycles:

$$
\begin{aligned}
Q_{t 1} & =\frac{\Delta_{1}}{4}\left(\mu_{1}-\mu_{2}\right), \\
Q_{m 1} & =\frac{\left(\mu_{1}-\mu_{2}\right)\left(2 \mu_{1}+\mu_{2}\right) \Delta_{1}}{4 \mu_{1}}, \\
Q_{s 1} & =\frac{\left(\mu_{1}-\mu_{2}\right) \Delta_{1}\left(3 \mu_{1}+\mu_{2}\right)}{4 \mu_{1}} .
\end{aligned}
$$

Furthermore, we can obtain the optimal profits of the manufacturer and the recycler as follows:

Definition

2

The base profit of the manufacturer for remanufacturing

The base profit of the recycler for refurbishing

Price of the recycler for recycling used products from consumers in Situations 1 and 2

rice of the manufacturer for recycling used products from consumers in Situations 1 and 2

The proportion of components that cannot be refurbished among the used products recycled by the recycler waste products recycled in Situations 1 and 2

Sensitivity coefficient of recycling volume affected by recycling price

Sensitivity coefficient of recycling volume affected by the cross-effect of recycling price of a different recycling channel

$$
\begin{aligned}
\pi_{m 1} & =\frac{\left(3 \mu_{1}+\mu_{2}\right) \Delta_{1}^{2}\left(\mu_{1}-\mu_{2}\right)}{8 \mu_{1}} \\
\pi_{t 1} & =\frac{\Delta_{1}^{2}\left(\mu_{1}-\mu_{2}\right)^{2}}{16 \mu_{1}}
\end{aligned}
$$

The total profit of the supply chain can be obtained.

$$
\pi_{s 1}=\frac{\Delta_{1}^{2}\left(\mu_{1}-\mu_{2}\right)\left(7 \mu_{1}+\mu_{2}\right)}{16 \mu_{1}} .
$$

Situation 2. Recyclers can refurbish.

In this situation, the profit functions of the manufacturer and the recycler are 


$$
\begin{gathered}
\pi_{m 2}=\left(\Delta_{1}-r_{m 2}\right)\left(\mu_{1} r_{m 2}-\mu_{2} r_{t 2}\right)+\left(\Delta_{1}-b_{2}\right) \theta\left(\mu_{1} r_{t 2}-\mu_{2} r_{m 2}\right), \\
\pi_{t 2}=\left(\Delta_{2}-r_{t 2}\right)(1-\theta)\left(\mu_{1} r_{t 2}-\mu_{2} r_{m 2}\right)+\left(b_{2}-r_{t 2}\right) \theta\left(\mu_{1} r_{t 2}-\mu_{2} r_{m 2}\right) .
\end{gathered}
$$

It is similar to the solution process in Situation 1. We can obtain the optimal decision of both the manufacturer and the recycler in Situation 2 and so on.

$$
\begin{aligned}
r_{m 2} & =\frac{\Delta_{1}}{2}, \\
b_{2} & =\frac{\Delta_{1}}{2}+\frac{\Delta_{2} \theta-\Delta_{2}}{2 \theta}, \\
r_{t 2} & =\frac{\Delta_{1} \mu_{2}}{4 \mu_{1}}+\frac{\left(\Delta_{1} \theta-\Delta_{2}(\theta-1)\right)}{4} .
\end{aligned}
$$

Then, we can get the number of recycling.

$$
\begin{aligned}
Q_{t 2} & =\frac{\left(\theta \Delta_{1}-\Delta_{2}(-1+\theta)\right) \mu_{1}-\mu_{2} \Delta_{1}}{4}, \\
Q_{m 2} & =\frac{2 \mu_{1}^{2} \Delta_{1}-\mu_{2}{ }^{2} \Delta_{1}-\mu_{2}\left(\theta \Delta_{1}-\Delta_{2}(-1+\theta)\right) \mu_{1}}{4 \mu_{1}},
\end{aligned}
$$

$$
Q_{s 2}=\frac{\left(\left((\theta+2) \Delta_{1}-(\theta-1) \Delta_{2}\right) \mu_{1}+\mu_{2} \Delta_{1}\right)\left(\mu_{1}-\mu_{2}\right)}{4 \mu_{1}} .
$$

Then, we can obtain the profits of the manufacturer and the recycler.

$$
\begin{aligned}
\pi_{m 2} & =\frac{2 \Delta_{1}^{2}\left(\mu_{1}^{2}-\mu_{2}^{2}\right)+\left(\left(\theta \Delta_{1}-\Delta_{2}(\theta-1)\right) \mu_{1}-\mu_{2} \Delta_{1}\right)^{2}}{8 \mu_{1}}, \\
\pi_{t 2} & =\frac{\left(\left(\theta \Delta_{1}-\Delta_{2}(\theta-1)\right) \mu_{1}-\mu_{2} \Delta_{1}\right)^{2}}{16 \mu_{1}}
\end{aligned}
$$

The total profit of the supply chain can be obtained.

$$
\pi_{s 2}=\frac{\left(\left(3 \theta^{2}+4\right) \Delta_{1}^{2}-6 \theta \Delta_{2}(\theta-1) \Delta_{1}+3 \Delta_{2}^{2}(\theta-1)^{2}\right) \mu_{1}^{2}-6 \mu_{2} \Delta_{1}\left(\Delta_{1} \theta-\Delta_{2}(\theta-1)\right) \mu_{1}-\mu_{2}^{2} \Delta_{1}^{2}}{16 \mu_{1}}
$$

Lemma 1. To ensure that the recycler's recycling quantity is greater than 0 , we can obtain $\Delta_{2} \mu_{1}(1-\theta)+\Delta_{1}\left(\mu_{1} \theta-\mu_{2}\right)>0$.

Proposition 1. Both the recycler and the manufacturer prefer the refurbish situation if and only if the recycler's base profit is greater than the manufacturer's base profit.

We used to think that the recycler will refurbish when the profit for refurbishing was greater than the transfer price. However, Proposition 1 shows that only when the recycler's profit for refurbishing is greater than the manufacturer's profit for remanufacturing, the recycler is willing to carry out refurbishment activities. And at this moment, the manufacturer is also willing to cooperate with the recycler with refurbishment capabilities. The explain for this counterintuitive conclusion is that we are used to competing and focusing on ourselves, ignoring the cooperation and the others. And from the quantitative analysis considering competition and cooperation simultaneously, it can be found that when some recycled products are refurbished by the recycler, the transfer price of the other part may be lowered by the manufacturer. When the recycler is actively participating in recycling because of the high benefit of refurbishing, the manufacturer does not need to pay a high transfer price. Therefore, to maximize profit, the recycler must combine the benefits of refurbishing with the benefits of manufacturer's remanufacturing. The manufacturer can save a certain amount of transfer costs, so the manufacturer is willing to cooperate with the recyclers.
Many companies are currently recycling and refurbishing $[17,43]$. And most studies show that companies that participate in recycling are profitable. However, the reality is that a large number of recyclers end up with poor operations. One of the reasons for this is that recyclers only consider competition with manufacturers when refurbishing and refurbish when the return on refurbishment is higher than the transfer price, leading to operational difficulties. In order to operate better, recyclers should cooperate with the manufacturer and refer to the manufacturer's remanufacturing revenue when refurbishing.

Based on Proposition 1, the following analysis will be carried out.

\section{Analysis}

We analyze the influences of the quality of recycled products and the base profits for refurbishing or remanufacturing on the equilibrium solution when the recycler can refurbish. Then, we compare the equilibrium solutions in the two situations.

\subsection{Influence of the Recycler's Base Profit and the Quality of Used Products}

Proposition 2. The influence of the recycler's base profit for refurbishment on the equilibrium solution under a refurbishment situation:

(1) $r_{m 2}$ has nothing to do with $\Delta_{2} . r_{t 2}$ and $\Delta_{2}$ are positively correlated 
(2) $b_{2}$ has a negative correlation with $\Delta_{2}$

(3) $\pi_{m 2}, \pi_{t 2}, \pi_{s 2}$, and $\Delta_{2}$ are positively correlated

(4) $Q_{s 2}$ and $\Delta_{2}$ are positively correlated

Proposition 2 (1) shows that the manufacturer recycling price has no business with the recycler's base profit for refurbishment. The recycler's recycling price increases with the growth of its base profit for refurbishment. It is not difficult to understand that when the base profit for refurbishment increases, the recycler will try to recycle more used products by increasing its recycling price. In addition, that is what consumers like to see.

Proposition 2 (2) shows that the transfer price will decrease as the recycler's base profit for refurbishment increases. The higher the basic profit for refurbishment is, the more enthusiastic the recycler is about recycling. The manufacturer does not need to increase the transfer price to give recyclers more incentives to recycle. Therefore, they will choose to lower the transfer price.

Proposition 2 (3) shows that as the recycler's base profit for refurbishment increases, the recycler can rely on refurbishment to achieve sustained profitable growth. The increase in the base profit for refurbishment will increase the revenue of the supply chain system because the system income increases. The manufacturer can also share part of the refurbishment revenue of the recycler by reducing the transfer payment in cooperation. Therefore, the increase in the base profit for refurbishment leads to increases in the profits of all parties. This shows that the stronger the basic profit for refurbishment is, the more beneficial it is to the supply chain.

Proposition 2 (4) shows that the increase in the basic profit of refurbishment drives an increase in the total recycling volume. From Proposition 2 (3), we know that the increase in the basic profit of refurbishment drives the increase in the total profit of the supply chain. Therefore, the supply chain has the strength and motivation to increase the total amount of recycling by increasing the recycling price. Increasing the total amount of recycling can improve the resource utilization ratio and reduce environmental pollution.

Proposition 3. The influence of used products' quality level on the equilibrium solution under refurbish situations:

(1) $r_{m 2}$ has nothing to do with $\theta . r_{t 2}$ and $\theta$ are negatively correlated.

(2) $b_{2}$ and $\theta$ are positively correlated.

(3) $\pi_{m 2}, \pi_{t 2}, \pi_{s 2}$, and $\theta$ are negatively correlated.

(4) $Q_{s 2}$ and $\theta$ are negatively correlated.

The proportion of nonrefurbished components $\theta$ reflects the integral quality level of used products to some extent. The larger $\theta$ is, the lower the integral quality.

Proposition 3 (1) shows that the manufacturer's recycling price has no business with the quality of used products. For the recycler, the larger $\theta$ is, the less recyclers can refurbish because a lower refurbishment rate will weaken the recycler's enthusiasm for recycling. Therefore, the recycler will lower the recycling price.
Proposition 3 (2) shows that transfer price $b_{2}$ increases as $\theta$ increases. When $\theta$ increases, the recycler is not actively recycling. At this time, the manufacturer will receive more products from the recycler. Therefore, the manufacturer is willing and able to provide the recycler with higher transfer payments in their cooperative recycling to encourage the recycler to increase recycling enthusiasm and recycle more products.

Proposition 3 (3) describes that the quality level of used products has the same effect on the profits of all parts. The higher the $\theta$, the lower the profit. An increase in $\theta$ means that the recycler's average income of unit product recycled decreases. So, the recycler profit will decrease. The manufacturer will transfer part of its profits to the recycler through cooperative recycling transfer payments to encourage recycler recycling. Moreover, the increase of $\theta$ also means that the average income of unit product recycled of the recycling system decreases, resulting in a decrease in the revenue of the entire supply chain system.

Proposition 3 (4) describes that the higher $\theta$ is, the lower the total recycling quantity. The decrease in the recycling system's revenue, as mentioned above, will lead to a decrease in recycling enthusiasm, and, therefore, the total recycling volume decreases.

In summary, the high refurbishment value and highquality level of recycled products can increase the price of product recycling, increase the profits of the recycler and the manufacturer, and increase the amount of recycling. Therefore, the manufacturer should pay attention to product quality when designing products. When consumers use products, they should cherish the products. Environmental protection agencies and public welfare organizations should do a good job in recycling publicity.

\subsection{Comparative Analysis of Optimal Solutions}

\section{Proposition 4. Analysis of recycling price.}

(1) Regardless of whether the recycler can refurbish, the manufacturer's recycling price is equal: $r_{m 1}=r_{m 2}$. In the case of recycler refurbishment, the price of the recycler is higher: $r_{t 1}<r_{t 2}$.

(2) Regardless of whether the recycler can refurbish, $r_{m 1}, r_{m 2}$ and $r_{t 1}, r_{t 2}$ are positively correlated with $\Delta_{1}$.

Proposition 4 (1) shows that regardless of whether the recycler can refurbish, the manufacturer's recycling price has not changed. After the recycler can refurbish, the recycler's recycling price is higher. As the market leader, the manufacturer has the right to prioritize pricing. The recycling price will be set based on its profit first, so the manufacturer's recycling price will not change. When the recycler can refurbish, the profit of the recycler will increase, and the profit margins of the recyclers will increase. In this situation, the recycler has sufficient capacity to increase the recycling price; therefore, we can conclude that the recyclers have a higher recycling price after they can refurbish.

Proposition 4 (2) shows that the manufacturer's basic profit for remanufacturing and recycling prices are positively correlated. An increase in the basic profit of remanufacturing will increase the manufacturer's enthusiasm for recycling. For a 
greater recycling volume, the manufacturer will enhance the recycling price and motivate the recycler to increase the recycling price by sharing profits with recyclers through cooperation. Because of the high transfer price, the recycler is also willing to increase the recycling price to recycle more.

\section{Proposition 5. Analysis of transfer price.}

(1) The transfer price is higher when the recycler does not refurbish: $b_{1}>b_{2}$.

(2) Regardless of whether the recycler can refurbish, $b_{1}$ and $b_{2}$ are positively correlated with $\Delta_{1}$.

Proposition 5 (1) indicates that the transfer price is higher when refurbishing is not available. When the recycler cannot refurbish, the recycler only undertakes the function of recycling. The manufacturer remanufactures all waste products. At this time, the manufacturer enjoys the profits brought by the remanufacturing of all waste products. When the recycler can refurbish, the remanufacturing amount of the manufacturer is reduced, which affects the manufacturer's remanufacturing revenue. From Proposition 4 (1), it can be seen that the manufacturer's recycling price will remain unchanged after the recycler can refurbish. Therefore, the manufacturer will lower the transfer price to make up for part of the revenue taken away by the recycler's refurbishment. Therefore, the transfer price is higher when there is no refurbishment capability.

Proposition 5 (2) shows that the higher the manufacturer's basic profit for remanufacturing, the higher the transfer price, regardless of whether the recycler can refurbish. The increase in basic profit for remanufacturing enhances the manufacturer's enthusiasm for recycling. Therefore, the manufacturer will raise the transfer price to give the recycler an incentive to recycle more used products. In other words, the high basic profit for remanufacturing can increase the manufacturer's enthusiasm to cooperate with the recycler.

Proposition 6. The total profit of the supply chain is higher when the recycler refurbishes: $\pi_{s 1}<\pi_{s 2}$.

Proposition 6 shows that the profits of the supply chain in the second situation are significantly greater than those in the first situation. It can be seen from Proposition 1 that both the manufacturer and the recycler's profits under Situation 2 are increased when the basic profit for refurbishing is higher than the basic profit for remanufacturing. Therefore, when the recycler can refurbish, the profit of the supply chain is better.

\section{Proposition 7. Analysis of the total recovered quantity:}

(1) The total recovery of the supply chain is higher when the recycler refurbishes: $Q_{s 1}<Q_{s 2}$

(2) Regardless of whether the recycler can refurbish, $Q_{s 1}$ and $Q_{s 2}$ are positively correlated with $\Delta_{1}$

Proposition 7 (1) shows that the total recovered quantity is better in Situation 2 than in Situation 1. From Proposition 6, the supply chain's profit in Situation 2 is better than that in Situation 1, so it will recycle more used products in Situation 2.
Proposition 7 (2) shows that the higher the manufacturer's basic profit for remanufacturing, the higher the total recycling quantity, regardless of whether the recycler can refurbish. It is easy to explain combining Proposition 4 (2). High recycling prices attract more recycling volume. Proposition 7 (2) also means that the increase in the basic profit of remanufacturing is beneficial for sustainability by enhancing the recovery amount.

In summary, refurbishing can raise the price, the total quantity of recycled products, and profits of each part when the basic profit for refurbishing is higher than the basic profit for remanufacturing. This means that refurbishment is beneficial to the recycler and the manufacturer and the consumers and the environment. The increase in basic profit for remanufacturing is also good for every part.

\section{Numerical Examples}

In this section, we further analyze the profits of the manufacturer and the recycler, the total profit of the supply chain, and the total recycling quantity in Situations 1 and 2 . Here, we assume that all used products recycled belong to the same brand and the same version for comparison. In particular, we specify the parameters as follows: $\mu_{1}=0.4, \mu_{2}$ $=0.2$, and $\theta=0.6$.

Figure 2 shows that when the recycler's base profit for refurbishment is higher than the manufacturer's basic profit for remanufacturing, the manufacturer is willing to cooperate with the recycler with refurbishment capabilities. The recycler is also willing to carry out refurbishment activities. This is the same as Proposition 1. When the basic profit of refurbishment is lower than the basic profit of remanufacturing, the conclusion is the opposite. In addition, it can be seen from the figure that the increase in the basic profit of refurbishing and remanufacturing is beneficial to the manufacturer and recycler, as described in Proposition 2 (3).

From Figure 3, it is found that when the recycler's base profit for refurbishment is greater than the manufacturer's basic profit for remanufacturing, the total profit of the supply chain in the second situation is higher than that in the first situation, consistent with Proposition 6. Figure 2 shows that when the basic profit of refurbishment is higher, the profit of the manufacturer and the recycler in the second situation is higher than that in the first situation. Therefore, the supply chain's profit in the second situation is also better than that in the first situation when recyclers carry out refurbishment activities. When the recycler's base profit for refurbishment is lower than the manufacturer's basic profit for remanufacturing, the conclusion is the opposite.

Figure 4 analyzes the impact of the basic profit of the manufacturer and the recycler on the total number of recycles in different situations. As shown in the figure, when the recycler's base profit for refurbishment is greater than the manufacturer's basic profit for remanufacturing, the total recovered quantity in the second situation is better than that in the first situation. In addition, this is consistent with Proposition 7 (1). Furthermore, the increase in the base profits for the remanufacturer and refurbishing promotes the increase in the total recycling volume, consistent with 

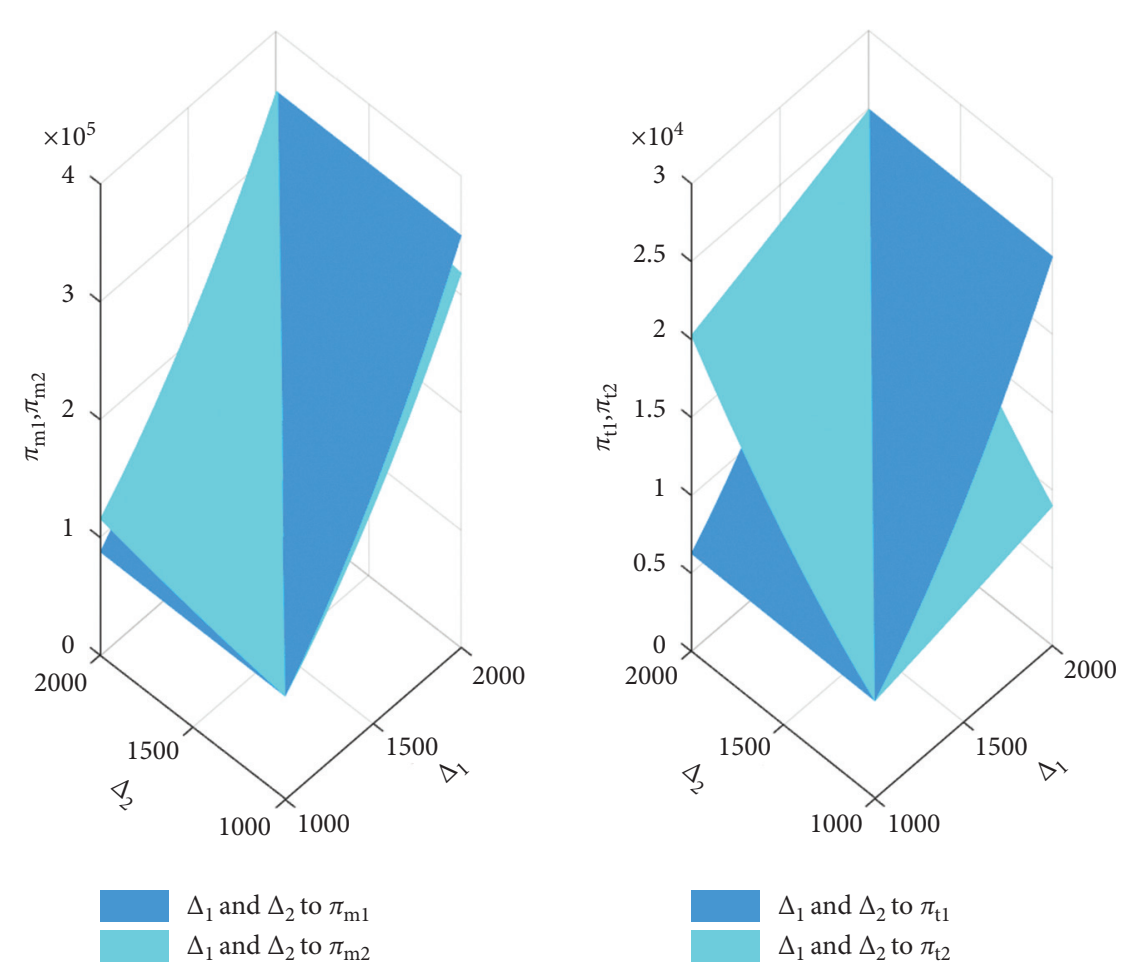

FIgURE 2: The impact of $\Delta_{1}$ and $\Delta_{2}$ on the profits of the manufacturer and the recycler.

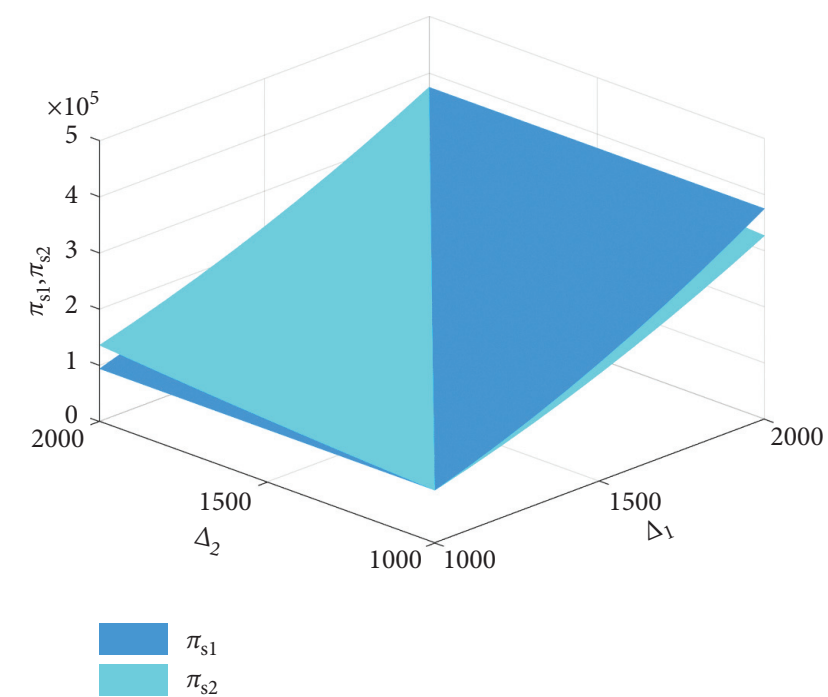

Figure 3: The impact of $\Delta_{1}$ and $\Delta_{2}$ on supply chain profits.

Proposition 2 (4) and Proposition 7 (2). When the recycler's base profit for refurbishment is lower than the manufacturer's basic profit for remanufacturing, the conclusion is the opposite.

\section{Conclusions}

Different from previous closed-loop supply chain studies, this article is in the context of competition and cooperation between the manufacturer and the recycler. We considered whether the recycler has the ability to refurbish and distinguished between refurbishment and

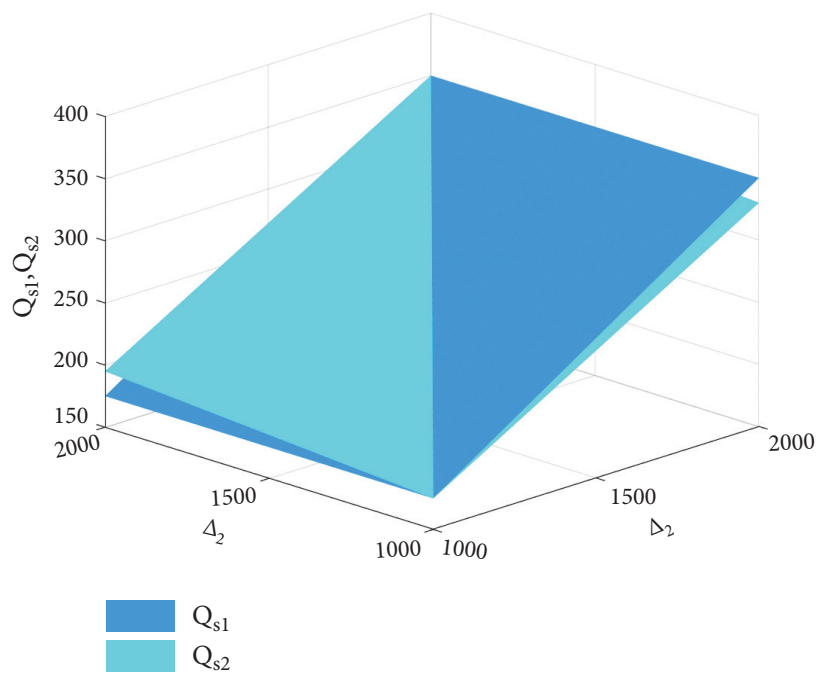

FIgURE 4: The influence of $\Delta_{1}$ and $\Delta_{2}$ on the total recovery quantity.

remanufacturing of two waste product disposal methods. Two dual-channel recycling models were constructed by comparing equilibrium solutions of two models. Then, the impacts of recycled products' quality and basic profits for remanufacturing and refurbishing on equilibrium solutions are discussed. Some conclusions and management insights are driven, which have certain guiding significance to increase each part's profit and improve resource utilization efficiency.

We found an interesting and counterintuitive conclusion: if the recycler refurbishes when his profit for refurbishing is greater than the profit for remanufacturing instead 
of that his profit for refurbishing is greater than the transfer payment from the manufacturer, both the recycler and the manufacturer can obtain more revenue. This indicates that whether recyclers carry out refurbishment or not, they should pay attention to their refurbishment income. If refurbishing income is high than remanufacturers' remanufacturing income, recyclers should carry out refurbishment activities. And at this moment, manufacturers should cooperate with recyclers with refurbishment ability. In addition, we found that when recyclers refurbish, the better the quality of WEEE, the higher the profits of recyclers and manufacturers on both sides. Therefore, both sides should remind consumers to protect products and keep their products' high quality.

Furthermore, we find that an increase in the basic profit of refurbishment and remanufacturing can increase the income of manufacturers and recyclers because they can share profits through waste product disposal cooperation, achieving a win-win situation. Therefore, both sides can try to increase their base profit level. This is beneficial to improve the profit of the supply chain, which in turn increases recycling prices and attracts consumers to recycling activities, thereby increasing recycling volumes. In other words, the higher profitability of refurbishment and remanufacturing can bring more profits to the supply chain, improve resource utilization efficiency, and reduce environmental pollution. Therefore, we should pay more attention to the profitability of refurbishment and remanufacturing.

This article only studies the impact of waste products' quality and bases profits on profits and prices. The research direction can be further expanded. For example, the prices of refurbished and remanufactured products affect each other when they are sold in the market; government subsidies for remanufacturing (compared to no subsidies for refurbishment); different market forces lead to different dominant players. These can be taken into consideration in future research.

\section{Appendix}

\section{Situation 1 Solution}

We can obtain $\partial^{2} \pi_{t 1} / \partial r_{t 1}^{2}=-2 \mu_{1}<0$, and then the function is concave on the decision variables $r_{t 1}$. Thus, there exists an optimal solution of equation (3). From the firstorder conditions, the optimal solution can be calculated as follows:

$$
r_{t 1}=\frac{b_{1} \mu_{1}+\mu_{2} r_{m 1}}{2 \mu_{1}}
$$

Substituting it into equation (2), we can derive an expression for $\pi_{m 1}$ in terms of $r_{m 1}$ and $b_{1}$. Considering the decision variables $r_{m 1}$ and $b_{1}$, the Hessian matrix of $\pi_{m 1}$ is $H=\left[\begin{array}{cc}\left(\mu_{2}^{2}-2 \mu_{1}^{2}\right) / \mu_{1} & \mu_{2} \\ \mu_{2} & -\mu_{1}\end{array}\right]$. Because $2\left(\mu_{1}^{2}-\mu_{2}^{2}\right)>0, \pi_{m 1}$ is jointly concave on $r_{m 1}$ and $b_{1}$. Therefore, we have the optimal solution as follows:

$$
\begin{aligned}
& b_{1}=\frac{\Delta_{1}}{2}, \\
& r_{m 1}=\frac{\Delta_{1}}{2} .
\end{aligned}
$$

Then, we obtain the optimal solution of the recycler's recycling price: $r_{t 1}=\Delta_{1} / 4+\mu_{2} \Delta_{1} / 4 \mu_{1}$.

Proof of Lemma 1. When the recycler can refurbish, the recycler's recycling amount should be greater than 0 . After substituting the reclaimed quantity, we can obtain the following: $\Delta_{2} \mu_{1}(1-\theta)+\Delta_{1}\left(\mu_{1} \theta-\mu_{2}\right)>0$.

Proof of Proposition 1. $\pi_{t 2}-\pi_{t 1}=1 / 16\left(\left(\mu_{1} \theta \Delta_{1}-\mu_{1} \theta \Delta_{2}+\right.\right.$ $\left.\left.\mu_{1} \Delta_{2}-\mu_{2} \Delta_{1}\right)+\Delta_{1}\left(\mu_{1}-\mu_{2}\right)\right)(\theta-1)\left(\Delta_{1}-\Delta_{2}\right)$. According to the Lemma 1, $\mu_{1} \theta \Delta_{1}-\mu_{1} \theta \Delta_{2}+\mu_{1} \Delta_{2}-\mu_{2} \Delta_{1}>0$. Combining $\mu_{1}>\mu_{2}>0$ and $0>\theta>1$, we can obtain if and only if $\Delta_{2} \geq \Delta_{1}$ and $\pi_{t 2}-\pi_{t 1} \geq 0$, which means that the recycler is willing to carry out refurbishment activities. The proof of the manufacturer is similar.

\section{Proof of Proposition 2.}

(1) The manufacturer's recycling price is $r_{m 2}=\Delta_{1} / 2 \cdot r_{m 2}$ has nothing to do with $\Delta_{2}$.

The recycler's recycling price is $r_{t 2}=\left(\left(\Delta_{1} \theta-\Delta_{2}(\theta-1)\right) \mu_{1}+\mu_{2} \Delta_{1}\right) / 4 \mu_{1}$, and its first derivative for $\Delta_{2}$ is equal to $\partial r_{t 2} / \partial \Delta_{2}=1-\theta / 4>0$. Therefore, the recycler's recycling price $r_{t 2}$ and base profit $\Delta_{2}$ are positively correlated.

(2) The transfer price is $b_{2}=\left(\theta \Delta_{1}+\theta \Delta_{2}-\Delta_{2}\right) / 2 \theta$, and its first derivative for $\Delta_{2}$ is $\partial b_{2} / \partial \Delta_{2}=(\theta-1) / 2 \theta<0$. The transfer price $b_{2}$ and the base profit of recycler $\Delta_{2}$ are negatively related.

(3) Deriving the manufacturer's profit to $\Delta_{2}$, we can obtain $\partial \pi_{m 2} / \partial \Delta_{2}=1 / 4\left(\mu_{1} \theta \Delta_{1}-\mu_{1} \theta\right.$ $\left.\Delta_{2}+\mu_{1} \Delta_{2}-\mu_{2} \Delta_{1}\right)(1-\theta)$. According to Lemma 1 , $\mu_{1} \theta \Delta_{1}-\mu_{1} \theta \Delta_{2}+\mu_{1} \Delta_{2}-\mu_{2} \Delta_{1}>0$; therefore, the manufacturer's profit is positively correlated with $\Delta_{2}$. Proofs on the left in this proposition are similar to this.

(4) The first derivative of the total recovered quantity to $\Delta_{2}$ is $\partial Q_{s 2} / \partial \Delta_{2}=1 / 4\left(\mu_{1}-\mu_{2}\right)(1-\theta)>0$. Therefore, the two parties are in a positive correlation.

Proof of Proposition 3.

(1) The remanufacturer's recycling price is $r_{m 2}=1 / 2$, and the proportion of nonrefurbished components $\theta$ does not affect the recycling price $r_{m 2}$.

The recycler's recycling price is $r_{t 2}=\Delta_{1} \mu_{2} / 4 \mu_{1}+\left(\Delta_{1} \theta-\Delta_{2}(\theta-1)\right) / 4$, and its firstorder partial derivative for $\theta$ is equal to $\partial r_{t 2} / \partial \theta=\left(\Delta_{1}-\Delta_{2}\right) / 4$. The authors have $\Delta_{2}>\Delta_{1}$. Therefore, $\partial r_{t 2} / \partial \theta>0$ and $r_{t 2}$ are negatively correlated with $\theta$. 
(2) The transfer price is $b_{2}=\left(\theta \Delta_{1}+\theta \Delta_{2}-\Delta_{2}\right) / 2 \theta$, and its first-order partial derivative for $\theta$ is equal to $\partial b_{2} / \partial \theta=\Delta_{2}^{2} / 2 \theta^{2}>0$. They are positively related.

(3) The manufacturer's profit is $\pi_{m 2}=\left(2 \Delta_{1}^{2} \mu_{1}^{2}-2 \Delta_{1}^{2} \mu_{2}^{2}+\right.$ $\left.\left(\theta \Delta_{1}-\Delta_{2}(\theta-1)-\mu_{2} \Delta_{1}\right)^{2}\right) / 8 \mu_{1}$, and the recycler's profit is $\pi_{t 2}=\left(\left(\theta \Delta_{1}-\Delta_{2}(\theta-1)\right) \mu_{1}-\mu_{2} \Delta_{1}\right)^{2} / 16 \mu_{1}$. The second-order derivative of $\pi_{m 2}$ to $\theta$ can be calculated by $\partial^{2} \pi_{m 2} / \partial \theta^{2}=\mu_{1}\left(\Delta_{1}-\Delta_{2}\right)^{2} / 4>0$. The second-order derivative of $\pi_{t 2}$ to $\theta$ can be calculated by $\partial^{2} \pi_{t 2} / \partial \theta^{2}=\mu_{1}\left(\Delta_{1}-\Delta_{2}\right)^{2} / 8>0$. Therefore, the profit functions of both parties are convex in $\theta$. We easily find that the extreme points of both parties are the same. In addition, the extreme point is $\vec{\theta}=\left(\mu_{2} \Delta_{1}-\mu_{1} \Delta_{2}\right) / \mu_{1}\left(\Delta_{1}-\Delta_{2}\right)>0$. Considering $0>\theta>1$, by comparing the extreme point with a size of 1 , we find that $\theta^{\prime}-1=\Delta_{1}\left(\mu_{1}-\mu_{2}\right) /\left(\Delta_{2}\right.$ $\left.-\Delta_{1}\right) \mu_{1}>0$, which shows that the extreme point is on the right side of 1 . Therefore, in the range of $0>\theta>1$, the profit of both the manufacturer and the recycler will decrease as $\theta$ increases. We find the first-order derivative of the overall profit of the supply chain to $\theta$ in the second situation: $\partial \pi_{s 2} / \partial \theta=3 / 8\left(\mu_{1} \theta \Delta_{1}-\mu_{1} \theta\right.$ $\left.\Delta_{2}+\mu_{1} \Delta_{2}-\mu_{2} \Delta_{1}\right)\left(\Delta_{1}-\Delta_{2}\right)$. Combining $\Delta_{2}>\Delta_{1}$ and $\mu_{1} \theta \Delta_{1}-\mu_{1} \theta \Delta_{2}+\mu_{1} \Delta_{2}-\mu_{2} \Delta_{1}>0$, the supply chain profit is negatively correlated with $\theta$.

(4) The first derivative of the total recovered quantity to $\theta$ is $\partial Q_{s 2} / \partial \theta=1 / 4\left(\mu_{1}-\mu_{2}\right)\left(\Delta_{1}-\Delta_{2}\right)>0$. Therefore, the two parties are in a negative correlation.

\section{Proof of Proposition 4.}

(1) We have $r_{m 1}=r_{m 2}=\Delta_{1} / 2$ and $r_{t 1}-r_{t 2}=1 / 4\left(\Delta_{1}-\right.$ $\left.\Delta_{2}\right)(1-\theta)<0$. Therefore, $r_{m 1}=r_{m 2}, r_{t 1}>r_{t 2}$.

(2) From the equilibrium solutions, it is easy to obtain $\partial r_{m 1} / \partial \Delta_{1}=\partial r_{m 2} / \partial \Delta_{1}=1 / 2>0$.

Proof of Proposition 5.

(1) We have $b_{1}-b_{2}=\Delta_{2}(1-\theta) / 2 \theta>0$. Therefore, $b_{1}>b_{2}$.

(2) The first derivative of the manufacturer's basic profit in different situations can be calculated as $\partial r_{m 1} / \partial \Delta_{1}=\partial r_{m 2} / \partial \Delta_{1}=1 / 2>0$.

Proof of Proposition 6. We have $\pi_{s 2}-\pi_{s 1}=3 / 16\left(\mu_{1} \theta \Delta_{1}-\right.$ $\left.\mu_{1} \theta \Delta_{2}+\mu_{1} \Delta_{2}-\mu_{2} \Delta_{1}+\Delta_{1}\left(\mu_{1}-\mu_{2}\right)\right)(\theta-1)\left(\Delta_{1}-\Delta_{2}\right)$. Simultaneously, $\mu_{1} \theta \Delta_{1}-\mu_{1} \theta \Delta_{2}+\mu_{1} \Delta_{2}-\mu_{2} \Delta_{1}>0, \quad \Delta_{2}>\Delta_{1}$, $\mu_{1}>\mu_{2}, 0<\theta<1$. We can get $\pi_{s 2}>\pi_{s 1}$.

\section{Proof of Proposition 7.}

(1) We have $Q_{s 1}-Q_{s 2}=1 / 4\left(\mu_{1}-\mu_{2}\right) \quad\left(\Delta_{1}-\Delta_{2}\right)$ $(1-\theta)<0$. Therefore, $Q_{s 1}<Q_{s 2}$.

(2) The first derivative of the manufacturer's basic profit in different situations can be calculated as follows:

$$
\begin{aligned}
& \partial Q_{s 1} / \partial \Delta_{1}=\left(3 \mu_{1}^{2}-2 \mu_{2} \mu_{1}-\mu_{2}^{2}\right) / 4 \mu_{1}>0, \\
& \partial Q_{s 2} / \partial \Delta_{1}=\left((\theta+2) \mu_{1}+\mu_{2}\right)\left(\mu_{1}-\mu_{2}\right) / 4 \mu_{1}>0 .
\end{aligned}
$$

\section{Data Availability}

The data used to support the findings of this study are included within the article.

\section{Conflicts of Interest}

The authors declare that they have no conflicts of interest.

\section{Acknowledgments}

This research was funded by the Sichuan Social Science Planning Project (Grant no. SC21C005).

\section{References}

[1] A. Yenipazarli, "Managing new and remanufactured products to mitigate environmental damage under emissions regulation," European Journal of Operational Research, vol. 249, no. 1, pp. 117-130, 2016.

[2] G. Li, L. Li, T. Choi, and S. P. Sethi, "Green supply chain management in Chinese firms: innovative measures and the moderating role of quick response technology," Journal of Operations Management, vol. 66, no. 7-8, 2019.

[3] Y. Huang and Z. Wang, "Information sharing in a closed-loop supply chain with technology licensing," International Journal of Production Economics, vol. 191, pp. 113-127, 2017.

[4] T. A. Yekeen, X. Xu, Y. Zhang et al., "Assessment of health risk of trace metal pollution in surface soil and road dust from e-waste recycling area in China," Environmental Science and Pollution Research, vol. 23, no. 17, pp. 17511-17524, 2016.

[5] R. C. Savaskan, S. Bhattacharya, and L. N. van Wassenhove, "Closed-loop supply chain models with product remanufacturing," Management Science, vol. 50, 2004.

[6] S. Sinha and N. M. Modak, "A systematic review in recycling/ reusing/remanufacturing supply chain research: a tertiary study," International journal of sustainable engineering, vol. 14, no. 6, pp. 1-22, 2021.

[7] E. Jafarian, J. Razmi, and R. Tavakkoli-Moghaddam, "Forward and reverse flows pricing decisions for two competing supply chains with common collection centers in an intuitionistic fuzzy environment," Soft Computing, vol. 23, no. 17, pp. 7865-7888, 2019.

[8] J. Zhao, C. Wang, and L. Xu, "Decision for pricing, service, and recycling of closed-loop supply chains considering different remanufacturing roles and technology authorizations," Computers \& Industrial Engineering, vol. 132, pp. 59-73, 2019.

[9] Y. Xiong, Y. Zhou, G. Li, H.-K. Chan, and Z. Xiong, "Don't forget your supplier when remanufacturing," European Journal of Operational Research, vol. 230, no. 1, pp. 15-25, 2013.

[10] N. M. Modak, S. Sinha, S. Panda, and N. Kazemi, “Analyzing a socially responsible closed-loop distribution channel with recycling facility," SN Applied Sciences, vol. 1, no. 10, 2019.

[11] Q. Zhou, C. Meng, and K. F. Yuen, "The impact of secondary market competition on refurbishing authorization strategies," International Journal of Production Economics, vol. 228, p. $107728,2020$.

[12] J. D. Abbey, M. G. Meloy, V. D. R. Guide, and S. Atalay, "Remanufactured products in closed-loop supply chains for 
consumer goods," Production and Operations Management, vol. 24, no. 3, pp. 488-503, 2015.

[13] M. Reimann, Y. Xiong, and Y. Zhou, "Managing a closed-loop supply chain with process innovation for remanufacturing," European Journal of Operational Research, vol. 276, 2019.

[14] X. Cao, X. Wang, and H. Wen, "Managing new and remanufactured products with remanufacturing degree under patent protection," Kybernetes, vol. 49, 2019.

[15] M. E. Ferguson and L. B. Toktay, "The effect of competition on recovery strategies," Production and Operations Management, vol. 15, pp. 351-368, 2006.

[16] G. Ferrer and J. M. Swaminathan, "Managing new and remanufactured products," Management Science, vol. 52, no. 1, pp. 15-26, 2006.

[17] H. Liu, M. Lei, T. Huang, and G. K. Leong, "Refurbishing authorization strategy in the secondary market for electrical and electronic products," International Journal of Production Economics, vol. 195, pp. 198-209, 2018.

[18] Y. Tang, Q. Zhang, Y. Li, G. Wang, and Y. Li, "Recycling mechanisms and policy suggestions for spent electric vehicles' power battery -A case of Beijing," Journal of Cleaner Production, vol. 186, pp. 388-406, 2018.

[19] H. Fallah, H. Eskandari, and M. S. Pishvaee, "Competitive closed-loop supply chain network design under uncertainty," Journal of Manufacturing Systems, vol. 37, pp. 649-661, 2015.

[20] E. Xing, C. Shi, J. Zhang, S. Cheng, J. Lin, and S. Ni, "Double third-party recycling closed-loop supply chain decision under the perspective of carbon trading," Journal of Cleaner Production, vol. 259, Article ID 120651, 2020.

[21] H. Liu, M. Lei, H. Deng, G. Keong Leong, and T. Huang, "A dual channel, quality-based price competition model for the WEEE recycling market with government subsidy," Omega, vol. 59, pp. 290-302, 2016.

[22] J. Zhao, J. Wei, and M. Li, "Collecting channel choice and optimal decisions on pricing and collecting in a remanufacturing supply chain," Journal of Cleaner Production, vol. 167, pp. 530-544, 2017.

[23] S. C. Bulmus, S. X. Zhu, and R. Teunter, "Competition for cores in remanufacturing," European Journal of Operational Research, vol. 233, no. 1, pp. 105-113, 2014.

[24] M. Huang, M. Song, L. H. Lee, and W. K. Ching, "Analysis for strategy of closed-loop supply chain with dual recycling channel," International Journal of Production Economics, vol. 144, no. 2 , pp. 510-520, 2013.

[25] L. Liu, Z. Wang, L. Xu, X. Hong, and K. Govindan, "Collection effort and reverse channel choices in a closed-loop supply chain," Journal of Cleaner Production, vol. 144, pp. 492-500, 2017.

[26] L. Feng, K. Govindan, and C. Li, "Strategic planning: design and coordination for dual-recycling channel reverse supply chain considering consumer behavior," European Journal of Operational Research, vol. 260, pp. 601-612, 2017.

[27] C. Li, L. Feng, and S. Luo, "Strategic introduction of an online recycling channel in the reverse supply chain with a random demand," Journal of Cleaner Production, vol. 236, p. 117683, 2019.

[28] Y. Yuan, J. Yang, Y. Li, and W. Li, "Necessary conditions for coordination of dual-channel closed-loop supply chain," Necessary conditions for coordination of dual-channel closedloop supply chain. Technological Forecasting and Social Change, Technol Forecast Soc, vol. 151, p. 119823, 2020.

[29] T. Efendigil, S. Önüt, and E. Kongar, "A holistic approach for selecting a third-party reverse logistics provider in the presence of vagueness," Computers \& Industrial Engineering, vol. 54, no. 2, pp. 269-287, 2008.

[30] K. Govindan, M. Palaniappan, Q. Zhu, and D. Kannan, "Analysis of third party reverse logistics provider using interpretive structural modeling," International Journal of Production Economics, vol. 140, no. 1, pp. 204-211, 2012.

[31] P. Yi, M. Huang, L. Guo, and T. Shi, "Dual recycling channel decision in retailer oriented closed-loop supply chain for construction machinery remanufacturing," Journal of Cleaner Production, vol. 137, pp. 1393-1405, 2006.

[32] A. J. Spicer and M. R. Johnson, "Third-party demanufacturing as a solution for extended producer responsibility," Journal of Cleaner Production, vol. 12, no. 1, pp. 37-45, 2004.

[33] I.-H. Hong, J.-F. Dang, and K.-W. Lin, "The equilibrium contract rent and reward money under incomplete information in reverse supply chains: a game theoretical approach and computational study," Computers \& Industrial Engineering, vol. 102, pp. 69-77, 2016.

[34] J. Wang, W. Li, N. Mishima, and T. Adachi, "Formalisation of informal collectors under a dual-recycling channel: a game theoretic approach," Waste Management \& Research, vol. 38, no. 5 , pp. 576-587, 2020.

[35] H. Wang, H. Han, T. Liu et al., “"Internet +" recyclable resources: a new recycling mode in China," Resources, Conservation and Recycling, vol. 134, pp. 44-47, 2018.

[36] X. Zhu, J. Wang, and J. Tang, "Recycling pricing and coordination of WEEE dual-channel closed-loop supply chain considering consumers' bargaining," International Journal of Environmental Research and Public Health, vol. 14, no. 12, p. 1578, 2017.

[37] D. Wu, J. Chen, P. Li, and R. Zhang, "Contract coordination of dual channel reverse supply chain considering service level," Journal of Cleaner Production, vol. 260, p. 121071, 2020.

[38] J.-M. Chen and C.-I. Chang, "The co-opetitive strategy of a closed-loop supply chain with remanufacturing," Transportation Research Part E: Logistics and Transportation Review, vol. 48, no. 2, pp. 387-400, 2012.

[39] J. Chen, L. L. T. Chan, and Y.-C. Cheng, "Gaussian process regression based optimal design of combustion systems using flame images," Applied Energy, vol. 111, pp. 153-160, 2013.

[40] C. Fang, Z. You, Y. Yang, D. Chen, and S. Mukhopadhyay, "Is third-party remanufacturing necessarily harmful to the original equipment manufacturer?" Annals of Operations Research, vol. 291, no. 1-2, pp. 317-338, 2020.

[41] Y. T. Chen, F. T. S. Chan, S. H. Chung, and W.-Y. Park, "Optimization of product refurbishment in closed-loop supply chain using multi-period model integrated with fuzzy controller under uncertainties," Robotics and Computer-Integrated Manufacturing, vol. 50, pp. 1-12, 2018.

[42] J. Vorasayan and S. M. Ryan, "Optimal price and quantity of refurbished products," Production and Operations Management, vol. 15, pp. 369-383, 2006.

[43] N. Wang, Q. He, and B. Jiang, "Hybrid closed-loop supply chains with competition in recycling and product markets," International Journal of Production Economics, vol. 217, pp. 246-258, 2018. 